ORIGINAL

\title{
No-touch pylorus-resecting pancreatoduodenectomy can reduce postoperative complications even in low volume center
}

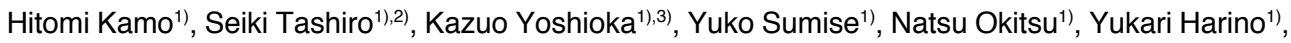 \\ Takeshi Yamaguchi' ${ }^{1,4)}$, Shizuo Ikeyama ${ }^{5)}$, and Akemi Yamanaka ${ }^{4)}$ \\ 1) Department of Surgery, Taoka Hospital, Tokushima, Japan, 2) Professor Emeritus, the University of Tokushima, Tokushima, Japan, ${ }^{3)}$ Clinical \\ Professor, Department of Digestive and Transplantation Surgery, the University of Tokushima Graduate School, Tokushima, Japan, 4) Department \\ of Anesthesiology and Emergency, Taoka Hospital, Tokushima, Japan, 5) Department of Interventional Radiology, Taoka Hospital, Tokushima, Japan
}

\begin{abstract}
Purposes : Pancreatoduodenectomy (PD) was performed for 6 periampullary cancer patients by using methods verified by quality randomized controlled trials (RCT) in a low-volume center (LVC). The purpose of this study was to verify the clinical results. Methods : No-touch pylorus-resecting pancreatoduodenectomy (PrPD), antecolic gastrojejunostomy, pancreatico-jejunostomy with a lost stent tube to the main pancreatic duct, and early removal of a prophylactic drain were performed. Results : The drain could be removed 4 days after operation, and no pancreatic fistula was observed in all cases. Solid food could be started on POD4 after removing the drain. Furthermore, postoperative systemic chemotherapy could be started earlier. Conclusion : Although we have only a few PD cases a year in our institution, PD can be conducted safely without complications by using the methods verified by quality RCTs. J. Med. Invest. 62 : 188-194, August, 2015
\end{abstract}

Keywords : No-touch pylorus-resecting pancreatoduodenectomy (PrPD), antecolic gastrojejunostomy, lost stent tube, early removal of drainage tube

\section{INTRODUCTION}

Our institution is a designated emergency hospital, renovated and relocated in March 2011.

From the opening of the hospital on March 1, 2011 to November 30,2013, 119 patients with digestive organ malignancies had undergone surgery, and 23 (19.3\%) of them had hepato-biliarypancreatic malignant surgery.

To achieve radical resection (R0) with safe procedures of pancreatoduodenectomy (PD) and fewer complications after surgery, since we have only several cases in our hospital, we decided to verify our surgical procedures for cancer of the pancreatic head region, reconstruction methods and postoperative management, referring to logical reports on highly evidence-based procedures conducted in high-volume centers (HVC) in literatures.

We adopted the surgical procedures described in 'Methods' below and performed PD in 6 cases. We report case series, regarding the breakdown of the 6 cases, five cases were cancer of the pancreas and one was that of the papilla of Vater.

\section{METHODS}

\section{Method of PD}

No-touch (1) pylorus-resecting pancreatoduodenectomy (PrPD) (2) with the hanging up and clamping technique (1) (Fig. 1A-D) was performed (Fig. 2). The advantages of this method are as follows,
(1) Able to operate the lesion without holding it by hand

(2) Able to prevent the leakage of cancer cells from the lesion without Kocher's mobilization

(3) Able to resect the retroperitoneal margin (RPM) systematically by forceps traction (Fig. 3)

(4) Able to ensure pathological exams to distinguish the nervous plexus near SMA from the lymphatic tissue

(5) Able to reduce the incidence of postoperative delayed gastric empting (DGE)

\section{Reconstruction Methods (Fig. 4, 5)}

(1) Pancreaticojejunostomy (Fig. 4)

a. Inner layer : Anastomosis of the pancreatic duct to the jejunal mucosa by 8 to 11 interrupted sutures using $5-0$ absorbable thread with a lost stent (internal drainage) tube (3)

b. Outer layer: Kakita's method (4) forming a seromuscular envelope with 5 to 6 interrupted sutures using 3-0 non-absorbable thread (prolene)

(2) Hepaticojejunostomy by one layer anastomosis with interrupted sutures using 3-0 or 4-0 absorbable thread without stent placement

(3) Antecolic gastrojejunostomy with 2-layer anastomosis (5)

(4) Only one closed-suction tube (Jackson-Pratt tube) was placed around the pancreaticojejunostomy

\section{Postoperative Management}

(1) Early Removal of Jackson-Pratt tube

Amylase value of the drainage fluid was measured on POD 1 and POD 4, and after confirming that the amylase value was not more than three times that of serum, the drainage tube was removed

Received for publication February 16, 2015 ; accepted March 23, 2015.

\section{Abbreviations}

SMA : superior mesenteric artery, SMV : superior mesenteric vein, PV : portal vein, CHA : common hepatic artery, SA : splenic artery, LGA : left gastric artery, LRV : left renal vein, IVC : inferior vena cava, IMV : inferior mesenteric vein, $\mathrm{PHA}$ : proper hepatic artery, RGA : right gastric artery, GDA : gastroduodenal artery, RGEA : right gastroepiproic artery, ASPDA : anterior superior pancreaticoduodenal artery
Address correspondence and reprint requests to Seiki Tashiro, MD, $\mathrm{PhD}$, Professor Emeritus, the University of Tokushima Medical Adviser of Taoka Hospital 4-2-2 Bandai-cho, Tokushima 770-0941, Japan and Fax : +81-88-655-3077. 
A

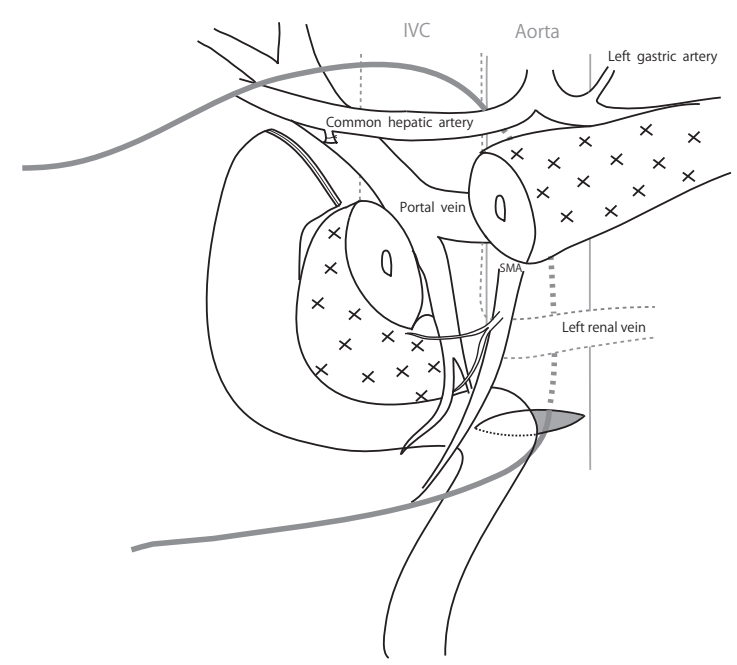

$\mathrm{C}$

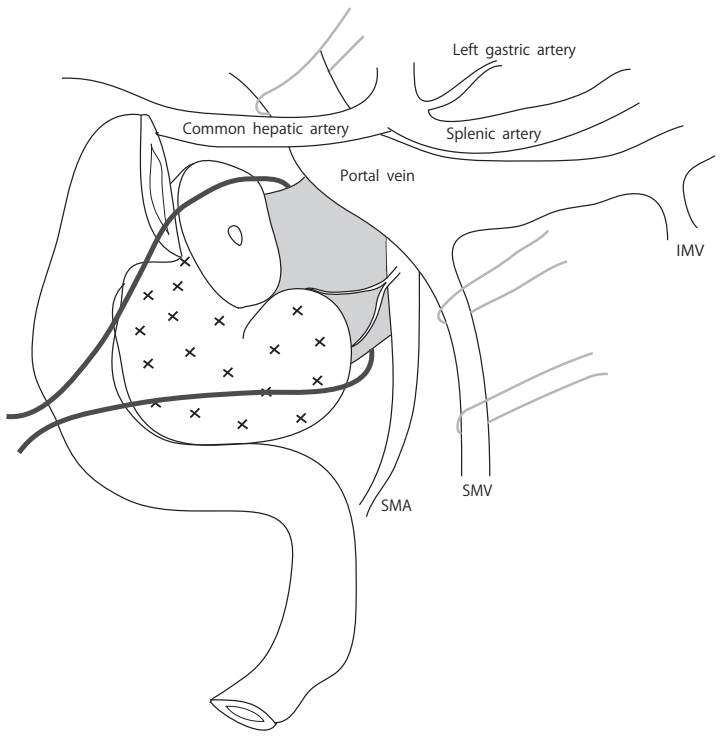

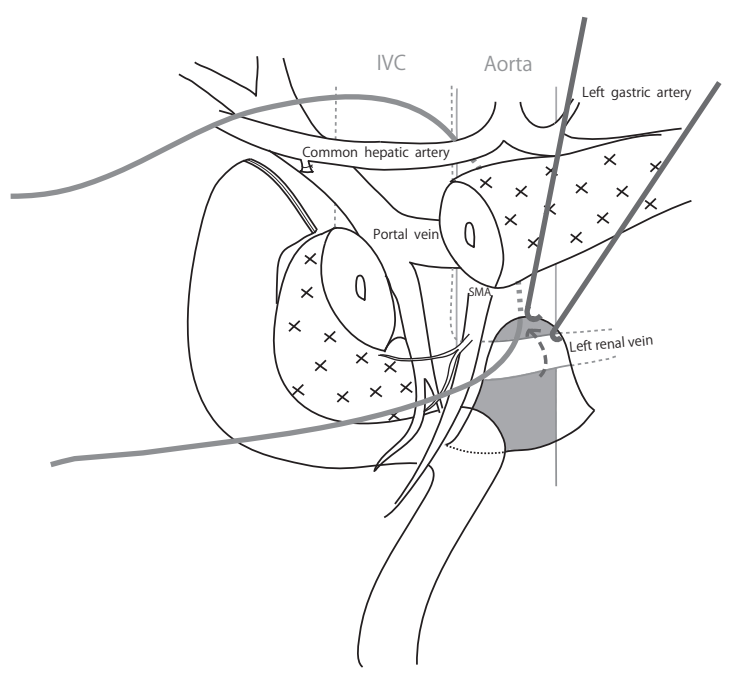

$\mathrm{D}$

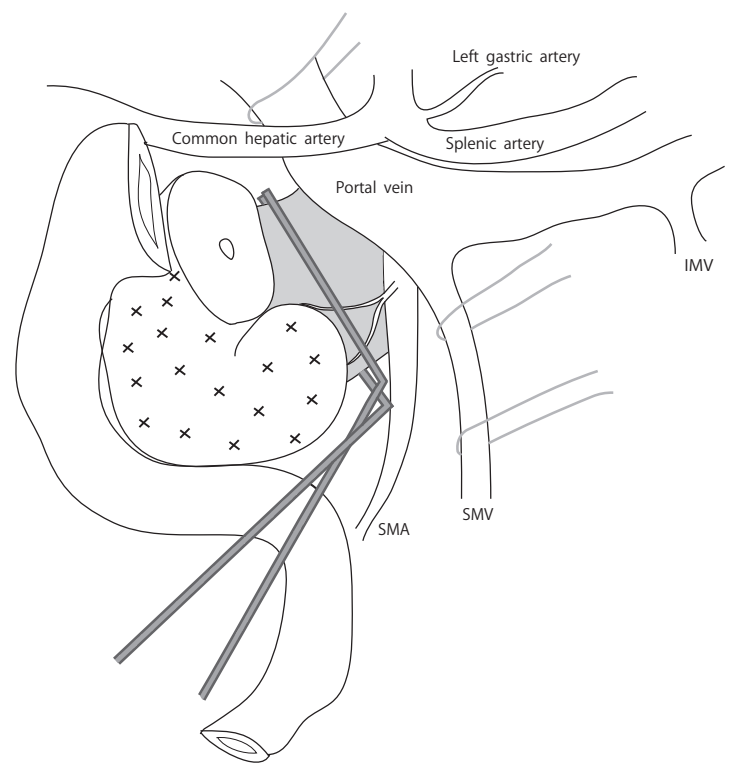

Fig. 1 No-touch pancreatoduodenectomy using the hunging up and clamping technique.

A. The anterior surfaces of the aorta is dissected bluntly to permit the passage of a tap

B. Since the left renal vein (LRV) is visible to the near comparatively when you pull the incised Treiz ligament with retractor, a position of the tape is changed into the ventral side of LRV from the dorsal side

$\mathrm{C}$. The tape is repositioned to the pancreatic side of the pancreatic side of the common hepatic artery and the SMV-PV cranially, and to the pancreatic side of the left renal vein and mesocolon caudally

D. Under traction of the vascular clamp, retroperitoneal margin is transected along with the right surface of SMA

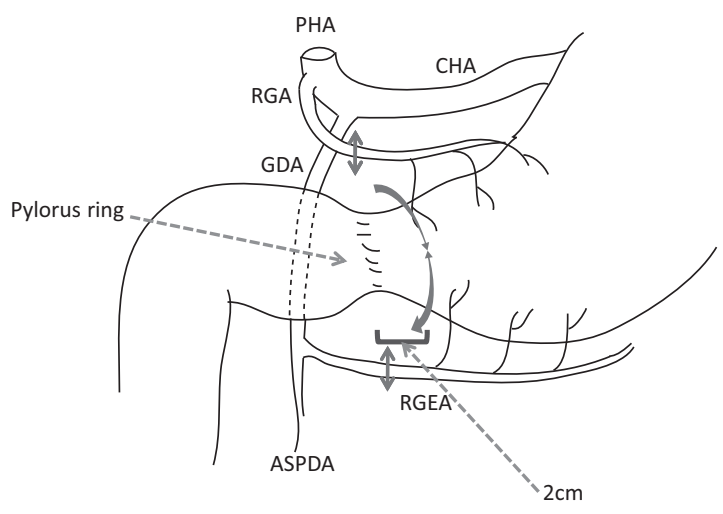

Fig. 2 The stomach is divided at $2 \mathrm{~cm}$ oral of the pylorus ring, and so more $90 \%$ of the stomach can be preserved. on POD 4.

(2) Introduction of enhanced recovery after surgery (ERAS)

Postoperative management was performed with ERAS method. A nasogastric tube was not inserted intra-and postoperatively. Postoperative pain was treated with a short-acting anesthetic and epidural analgesia. Fluid was taken orally the next day, followed by solid food intake on POD 3 and 4, and early mobilization and walking were encouraged.

\section{RESULTS}

During 33 months from the opening of our new hospital, PD had been performed in 6 patients. Table 1 describes the preoperative characteristics of the 6 patients. The average age was $62.8 \pm 11.7$ years old, and both the number of male patients and that of female 
A

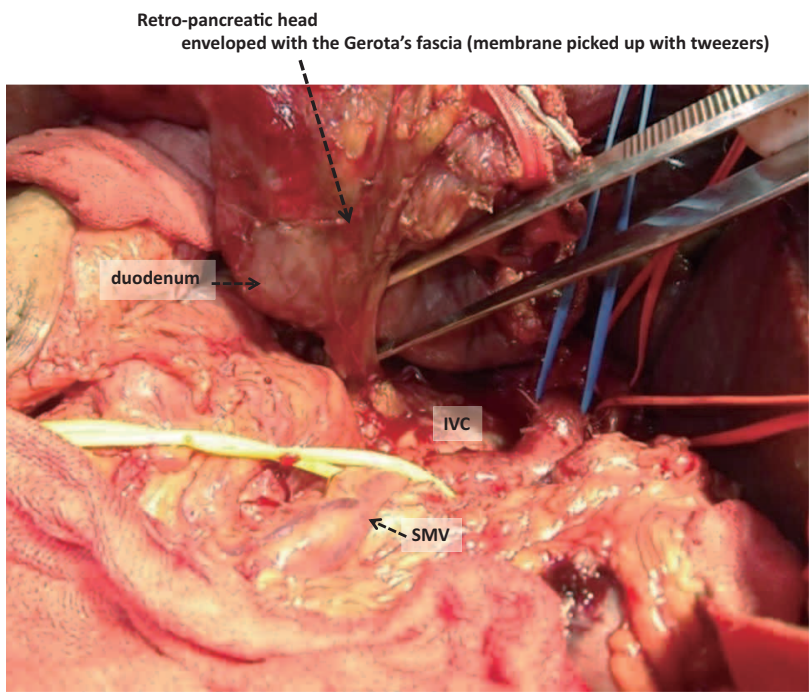

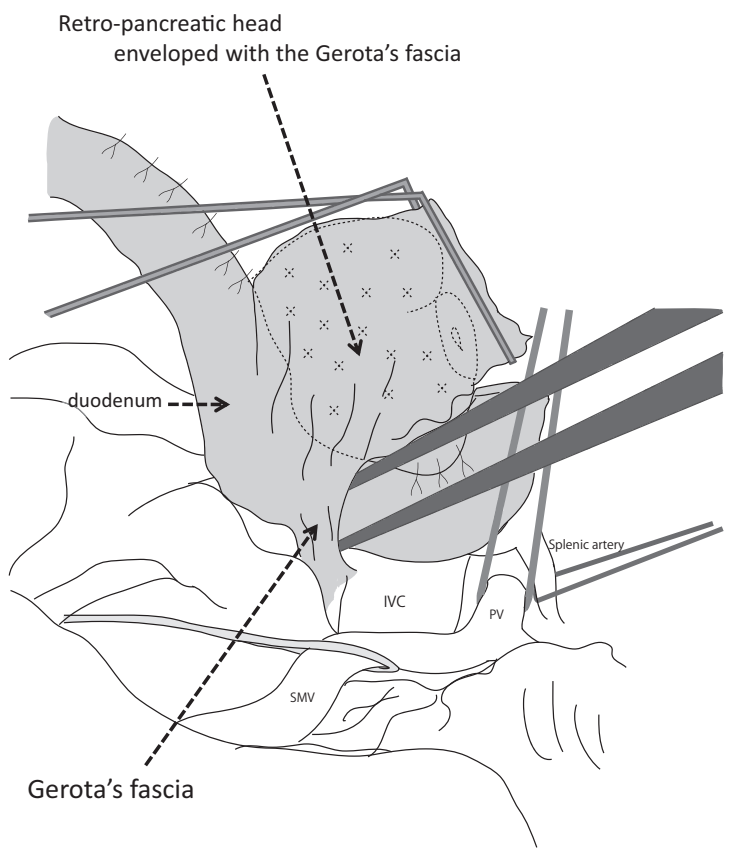

Fig. 3A. B The last procedure of the resection includes reversed Kocher's mobilization. The posterior plane of the Georta's fascia is dissected medial to lateral direction.

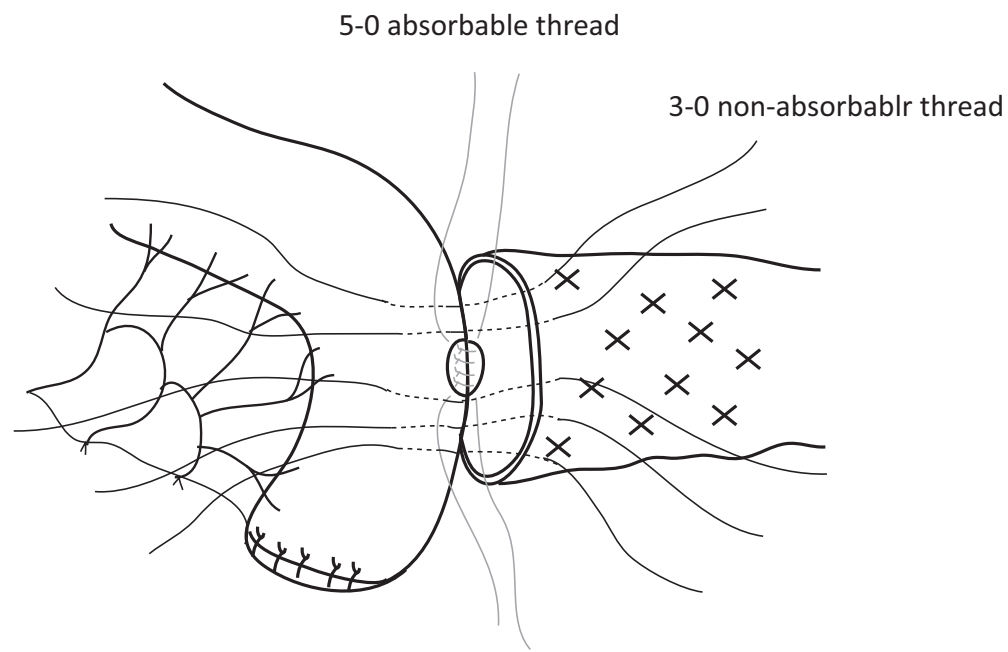

Fig. 4 Pancreaticojejunostomy was performed by duct-to-mucosa, end-to-side anastomosis in all patients.

patients were 3 . As for the preoperative performance status (PS), PS 0 is five people and PS 2 is one. Preoperative biliary drainage was conducted in 5 patients who had jaundice. The surgical details are shown in Table 2. The type of resection was PrPD in all cases, the operative time was $371.2 \pm 57.53 \mathrm{~min}$. The average bleeding volume was $464.6 \mathrm{ml} \pm 123.1$ and the intra-operative red cell transfusion of $3 \pm 1.7$ unit underwent in four cases. But blood transfusion was not done in two cases. Table 3 describes the state of intraoperative pancreas. The texture of the pancreas was hard with the diameter of the main pancreatic duct (MPD) to be 4 or $3.5 \mathrm{~mm}$ in 2 cases, and soft with the diameter of MPD to be $2 \mathrm{~mm}$ or $3.5 \mathrm{~mm}$ in 2 cases, respectively. Pancreatic transection was performed with ultrasonic scalpel (SonoSurg ${ }^{\circledR}$ ) and surgical knife around the main pancreatic duct.

The breakdown of the intra-and post-operative findings is as follows (Table 4). Cancer infiltration to the nervous plexus around SMA was not verified histologically in all 6 cases, but cancer infiltration of the dissected peripancreatic tissue margin was recognized in 3 of 6 cases. Therefore, the residual tumor was supposed to be evaluated as R1 but not R0 for advanced cancer in these 3 cases.

Postoperative amylase levels in serum and drainage fluid are shown in Table 5 . The serum levels on POD 4 were restored to the normal range except one which had no measurement. The amylase level of drainage fluid on POD 4 was lower than on POD 1 in 4 cases. Although the level on POD 4 was slightly higher than on POD 1 in 2 cases, they were almost in the normal range. According 


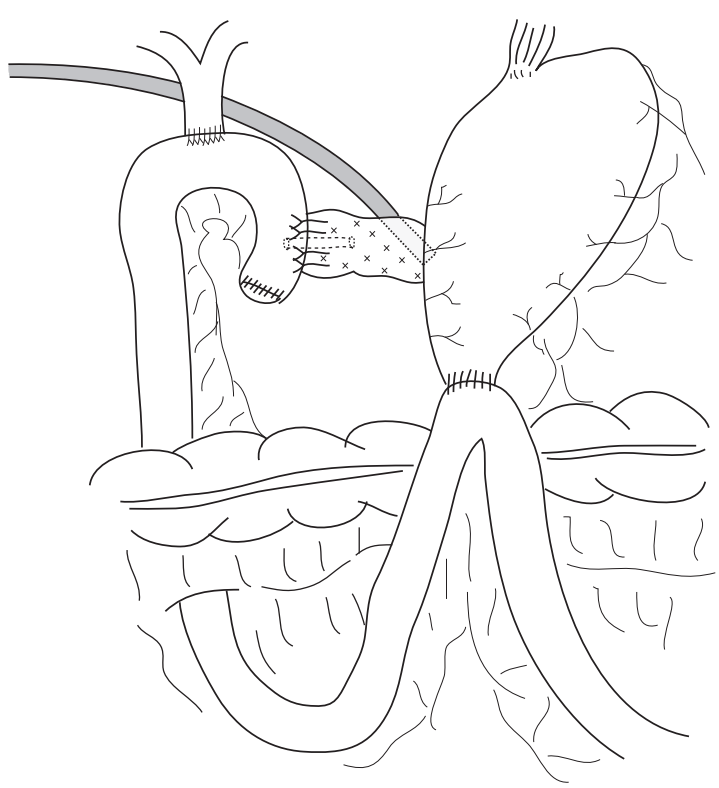

Fig. 5 Reconstruction after pylorus-ring resection PD.

Table 1 Preoperative Characteristics of 6 Patients

\begin{tabular}{lc}
\hline Age (yr) & $62.8 \pm 11.7$ \\
Gender (M/F) & $3 / 3$ \\
Performance Status (0/1/2) & $5 / 0 / 1$ \\
Diabetes (yes/no) & $2 / 4$ \\
Preoperative biliary drainage (yes/no) & $5 / 1$ \\
Total bilirubin at hospitalization (mg/dl) & $13.02 \pm 12.0$ \\
Total bilirubin at just before operation (mg/dl) & $2.49 \pm 1.24$ \\
Serum amylase level (IU/ML) & $89.17 \pm 53.43$ \\
\hline
\end{tabular}

Table 2 Surgical Details

\begin{tabular}{lc}
\hline Type of Resection & PrPD in 6 cases \\
Operation time (min. $\pm \mathrm{SD})$ & $371.2 \pm 57.53$ \\
Bleeding Volume (ml \pm SD) & $464.6 \pm 123.1$ \\
Intraoperative Red Cells Transfusions (yes/no) & $4 / 2$ \\
& $(\mathrm{U} \pm \mathrm{SD})$ \\
\hline
\end{tabular}

\section{DISCUSSION}

$\mathrm{PD}$ is an only effective treatment method for cancer of the pancreatic head region. Even for patients who underwent radical resection (R0), which was supposed to be curative, survival analysis has revealed a poor survival rate because of cancer recurrence. The most of the postoperative recurrent cases are due to hepatic metastasis, local recurrence, and peritoneal dissemination. One of the reasons for these is that cancer cells may be squeezed and shed into the portal vein, peritoneal cavity or retroperitoneum after duodenal mobilization during operation by holding the pancreatic head

Table 3 State of Residual Pancreas

\begin{tabular}{|c|c|c|c|c|c|c|c|}
\hline \multirow[t]{2}{*}{ No } & \multirow[t]{2}{*}{ Case } & \multirow[t]{2}{*}{ Location of cancer } & \multirow[t]{2}{*}{ Size of Tumor mm (TS) } & \multirow[t]{2}{*}{ Texture } & \multirow[t]{2}{*}{ Diameter of MPD } & \multicolumn{2}{|c|}{ Number of Interupted Sutures in } \\
\hline & & & & & & $\begin{array}{l}\text { Duct-to-duct } \\
\text { Anastomosis }\end{array}$ & $\begin{array}{l}\text { Seromuscular } \\
\text { Anastomosis* }\end{array}$ \\
\hline 1 & $60 \mathrm{~s} \mathrm{M}$ & $\mathrm{Ph}$ & $32 \times 35 x 35$ (TS2) & hard & $4 \mathrm{~mm}$ & 9 & 6 \\
\hline 2 & $60 \mathrm{~s} \mathrm{~F}$ & $\mathrm{Ph}$ & $58 \times 30 \times 21$ (TS3) & hard & $3.5 \mathrm{~mm}$ & 9 & 6 \\
\hline 3 & 40s M & Up & $55 \times 25 x 21$ (TS3) & soft & $2 \mathrm{~mm}$ & 8 & 6 \\
\hline 4 & $70 \mathrm{~s} \mathrm{~F}$ & $\mathrm{Ph}$ & 50x35x25 (TS3) & soft & $3.5 \mathrm{~mm}$ & 9 & 6 \\
\hline 5 & $70 \mathrm{~s} \mathrm{M}$ & $\mathrm{Ph}$ & 40x37x21 (TS2) & soft & $3.5 \mathrm{~mm}$ & 11 & 5 \\
\hline 6 & $60 \mathrm{~s} \mathrm{~F}$ & Papilla Vater & $23 \times 16$ & soft & $2 \mathrm{~mm}$ & 9 & 6 \\
\hline
\end{tabular}

$\mathrm{Ph}:$ Head of Pancreas, Up : Uncinate Process,

MPD : main pancreatic duct, *Kakita method : forming a seromuscular envelope 
Table 4 Description of Findings in 6 cases with PrPD

\begin{tabular}{ccccccc}
\hline No & Case & Disease & Ca. Inf. to SMA's NP & Ca. Inf. to DPM & Stage (TNM) & Assessment of Residual Tumor \\
\hline 1 & $60 \mathrm{~s} \mathrm{M}$ & Ca. of Ph & no & + & Stage III (T3N1M0) & R1 \\
2 & $60 \mathrm{~s} \mathrm{~F}$ & Ca. of Ph & no & + & Stage IV a (T3N2M0) & R1 \\
3 & $40 \mathrm{~s} \mathrm{M}$ & Ca. of Up & no & + & Stage IVb (T4N2M0) & R1 \\
4 & $70 \mathrm{~s} \mathrm{~F}$ & Ca. of Ph & no & - & Stage IV a (T3N2M0) & R0 \\
5 & $70 \mathrm{~s} \mathrm{M}$ & Ca. of Ph & no & - & Stage IV a (T3N2M0) & R0 \\
6 & $60 \mathrm{~s} \mathrm{~F}$ & Ca.of Papilla Vater & no & - & Stage III (T3N0M0) & R0 \\
\hline
\end{tabular}

PrPD : Pylorus-resecting Pancreatoduodenectomy,

Ca. : cancer, Inf. : Infiltration, $\mathrm{Ph}:$ Head of Pancreas, Up : Uncinate Process,

SMA : Superior Mesenteric Artery, NP : Nerve Plexus, DPM : Dissected peripancreatic tissue Margin

Table 5 Amylase levels in Serum and Drainage Fluid

\begin{tabular}{cc|c|c|c|c}
\hline No & Case & Amylaze levels (IU/ML) Serum*/Drainage Fuluid & Rempved Day of Drainage Tube & Hospital Stay (Days) \\
\hline & & POD 1 & POD 4 & 4 & 33 \\
\hline 1 & 60 s M & $157 / 109$ & $125 / 169$ & 4 & 14 \\
2 & 60 s F & NM/229 & $50 / 106$ & 4 & 23 \\
3 & 40 s M & $79 / 2888$ & $20 / 53$ & 4 & 21 \\
4 & 70 s F & $54 / 24$ & $20 / 11$ & 4 & 15 \\
5 & 70 s M & $146 / 398$ & $24 / 69$ & 4 & 80 \\
6 & 60 s F & $496 / 37$ & NM/65 & Median hospital stay 22 days \\
\hline
\end{tabular}

* Normal range : 42 158 IU/ NM : not mesure

Table 6 Postoperative Complications $(\mathrm{n}=6)$

\begin{tabular}{l|c}
\hline \multicolumn{1}{c|}{ Complications } & Number of Cases \\
\hline Pancreatic fistula & 0 \\
Biliary leakage & 0 \\
Intra-abdominal infection & 0 \\
Wound infection & 0 \\
Delayed gastric empting & 0 \\
Mortality & 0 \\
\hline
\end{tabular}

Table 7 Postoperative chemotherapy and Prognosis

\begin{tabular}{|c|c|c|c|c|c|c|c|c|}
\hline \multirow[t]{2}{*}{ No } & \multirow[t]{2}{*}{ Case } & \multirow[t]{2}{*}{ Stage } & \multirow[t]{2}{*}{ Location of ca. } & \multirow[t]{2}{*}{$\begin{array}{l}\text { Assessment of } \\
\text { Residual Tumor }\end{array}$} & \multicolumn{2}{|c|}{ Chemotherapy Drug \& start date } & \multicolumn{2}{|c|}{ Reccurence and Prognosis } \\
\hline & & & & & Drug & Days (POD) & Reccurence site & Prognosis \\
\hline 1 & $60 \mathrm{~s} \mathrm{M}$ & Stage III & $\mathrm{Ph}$ & $\mathrm{R} 1$ & $\mathrm{GEM}+\mathrm{S} 1$ & 14 & $\begin{array}{l}\text { Paraaorta LN } \\
\text { (19 month) }\end{array}$ & 39 month dead \\
\hline 2 & $60 \mathrm{~s} \mathrm{~F}$ & Stage IV a & $\mathrm{Ph}$ & $\mathrm{R} 1$ & GEM+S1 & 28 & $\begin{array}{l}\text { PL sma } \\
\text { (12 month) }\end{array}$ & 26 month dead \\
\hline 3 & $40 \mathrm{~s} \mathrm{M}$ & Stage IVb & Up & $\mathrm{R} 1$ & $\mathrm{GEM}+\mathrm{S} 1$ & 35 & $\begin{array}{l}\text { Liver metastasis } \\
\quad(2 \text { month })\end{array}$ & 10 month dead \\
\hline 4 & $70 \mathrm{~s} \mathrm{~F}$ & Stage IVa & $\mathrm{Ph}$ & R0 & S1 & 21 & $\begin{array}{c}\text { PL sma } \\
\text { (18 month) }\end{array}$ & 18 month alive \\
\hline 5 & $70 \mathrm{~s} \mathrm{M}$ & Stage IVa & $\mathrm{Ph}$ & R0 & - & - & $\begin{array}{l}\text { PL sma } \\
\text { (5 month) }\end{array}$ & 6 month dead \\
\hline 6 & $60 \mathrm{~s} \mathrm{~F}$ & Stage III & Papilla Vater & $\mathrm{R} 0$ & - & - & - & 8 month alive \\
\hline
\end{tabular}

$\mathrm{Ph}$ : Head of Pancreas, Up : Uncinate Process, GEM : Gemcitabine,

$\mathrm{S} 1$ : S1-tegafur-oxonate combination LN : Lymph node, PL sma : Plexus of superior mesenteric artery
No-touch PD using the hanging up and clamping technique by Hirota M, et al. (1) is considered to be a logical surgical method, since this procedure needs no duodenal mobilization or holding the pancreatic head. Therefore, we decided to adopt this method (Fig 1).

Recently, Hirota M (6) reported good results that the 5-year survival rate of patients who received PD was $44 \%$, and those of JPSstage III was $57 \%$.

PpPD with preservation of the entire stomach had been popularized in the late 1970s since the report on the treatment of chronic pancreatitis by Traverso (7). The results of several randomized controlled trials (RCT) or meta-analyses comparing PpPD and PD had been reported, and the two procedures were equivalent in regard to morbidity, mortality, and survival for the treatment of periampullary cancer (8-13). Moreover, PpPD has been reported to reduce 
dumping, diarrhea, and bile reflux gastritis after gastrectomy and improved the nutritional status of patients compared with PD with distal gastrectomy $(8,11,14)$. Therefore, $\mathrm{PpPD}$ had been generally accepted as a surgical procedure for periampullary cancer and also pancreatic cancer.

However, the reported overall incidence of delayed gastric emptying (DGE) according to new definition from the International Study Group of Pancreatic Surgery (ISGPS) is 33\% to $46 \%$ (15-18) and DGE is a frustrating complication. A RCT on whether PrPD could reduce the incidence of DGE compared with PpPD was performed by Kawai M, et al. (2), and showed that PrPD significantly reduced the incidence of DGE compared with PpPD. And then, a RCT conducted by Tani M, et al. (5) on whether antecolic duodenojejunostomy during PpPD could reduce the incidence of DGE compared with retrocolic anastomosis showed that antecolic reconstruction for duodenojejunostomy decreased DGE. Therefore, our institution decided to employ PrPD and antecolic gastrojejunostomy.

$\mathrm{PD}$ is an aggressive surgery occasionally associated with pancreatic fistula and postoperative mortality. Pancreatic fistula, in particular, is a severe complication of PD and may cause intraabdominal hemorrhage and postoperative mortality due to the autolytic activity of pancreatic juice. Thus, our institution started to use pancreaticojejunostomy with 2-layer anastomosis to prevent pancreatic fistula. The inner layer anastomosis of the pancreatic duct to the jejunal mucosa is performed and Kakita's method (4) is used for the outer layer anastomosis. Many surgeons have used an external stent across pancreaticojejunostomy into the MPD to prevent pancreatic fistula. In a RCT, Poon et al. (19) found that patients with an external tube had a significantly lower pancreatic fistula rate compared with the non-stented group, and the pancreatic texture did not affect the incidence of pancreatic fistula. By contrast, another RCT showed that pancreatic duct stenting did not decrease the occurrence of pancreatic fistula in patients who underwent PD, compared with non-stented patients (20). A RCT conducted by Tani M, et al. (3) on whether internal drainage with pancreaticojejunostomy is better than external drainage with pancreaticojejunostomy showed that the incidence of postoperative complications including pancreatic fistula was not significantly different between internal and external drainage. However the median postoperative hospital stay in the internal drainage group was significantly shorter than the external drainage group.

The International Study Group of Pancreatic Surgery (ISGPS) has proposed a consensus on the definition and clinical grading of postoperative pancreatic fistula (POPF). Actually, POPF represents a failure of healing/sealing of a pancreatic-enteric anastomosis or a parenchymal leak which is not directly related to an anastomosis since distinguishing the two conditions is difficult. Thus, the allinclusive definition is a drain output of any measurable volume of fluid on or after POD 3 with an amylase level higher than 3 times the serum amylase level. Pancreatic fistula is also defined as follows : Grade A, called "transient fistula," which has no clinical impact on postoperative course ; Grade B, required a change in management or adjustment in the clinical pathway ; Grade $\mathrm{C}$, a major change in clinical management or deviation from the normal clinical pathway $(21,22)$.

Then, to assess the value of prophylactic drainage, Kawai M, et al. (23) prospectively assigned the patients into 2 groups : In group $1(n=52)$, the drain was removed on POD 8 ; In group $2(n=52)$, the drain was removed on POD 4. Postoperative complications in the 2 groups were compared, and it was showed that the rate of pancreatic fistula was significantly lower in PDO 4 group (3.6\%) than POD 8 group $(23 \%),(p=0.0038)$. In addition, Grade $\mathrm{C}$ was not seen in POD 4 group. Also, a RCT on early versus late drain removal after $\mathrm{PD}$ was performed by Bassi $\mathrm{C}$ et al. (24). Early drain removal (on POD 3) in group $A(n=57)$ and late drain removal (POD 5 or beyond) in group B $(n=57)$ were allocated at random and compared. The rate of pancreatic fistula was $1.8 \%$ (Grade B in 1 case) in Group A versus 26.6\% (Grade C in 15 cases, Grade B in 1 case, and Grade A in 7 cases) in Group B (p=0.0001). They concluded that an intra-abdominal drain can be safely removed on POD 3 after PD, and a prolonged period of drain insertion is associated with a higher rate of postoperative complications with increased hospital stay and costs.

According to the Pancreatic Cancer Clinical Practice Guidelines (2013 Japanese version, Japan Pancreas Society) (25), complications tend to be fewer in the facilities where there are more than a certain number of treatment cases and specialists. In addition, those facilities conduct better management of complications, and are recommended as Grade B. However, there is no clear description about 'a certain number' of operations. In one paper, medical institutions with 19 or less cases in a year are determined to be a low-volume center (LVC), and those with 20 or more cases in a year to be high-volume center (HVC), and there is another paper that determined medical institutions with 4 or less cases to be LVC, those with 5 to 18 cases to be medium-volume center (MVC), and those with 19 or more cases to be HVC. There seems to be no formal and common definition for LVC, MVC and HVC. Some institutions have specialists even if they are LVC.

Although we have a few PD cases a year in our institution, PD can be conducted safely without complications by using the methods verified by the quality RCTs mentioned above. This indicates that even if a medical institution is not HVC, PD can be performed safely.

\section{CONFLICT OF INTEREST STATEMENT}

Hitomi Kamo and other co-authors have no conflict of interest.

\section{REFERENCES}

1. Hirota M, Kanemitsu K, Takamori H, Chikamoto A, Tanaka H, Sugita H, Sand J, Nordback I, Baba H : Pancreatoduodenectomy using a no-touch isolation technique. Am J Surg 199 : e65-e68, 2010

2. Kawai M, Tani M, Hirono S, Miyazawa M, Shimizu A, Uchiyama K, Yamaue $\mathrm{H}$ : Pylorus ring resection reduces delayed gastric emptying in patients undergoing pancretoduodenectomy ; A prospective, randomized, controlled trial of pylorus-resecting versus pylorus-preserving pancreatoduodenectomy. Ann Surg 253 : 495-501, 2011

3. Tani M, Kawai M, Hirono S, Ina S, Miyazawa M, Shimizu A, Yamaue $\mathrm{H}$ : A prospective randomized controlled trial of internal versus external drainage with pancreaticojejunostomy for pancretoduodenectomy. Am J Surg 199 : 759-764, 2010

4. Kakita A, Takahashi T, Furuta K : A simpler and more reliable technique of pancreatojejunal anastomosis. Surg Today 26 : 532-535, 1996

5. Tani M, Terasawa H, Kawai M, Ina S, Hirono S, Uchiyama $\mathrm{K}$, Yamaue $\mathrm{H}$ : Improvement of delayed gastric emptying in pylorus-preserving pancreatoduodenectomy ; results of a prospective, randomized, controlled trial. Ann Surg 243 : 316320, 2006

6. Hirota $\mathrm{M}$, Ogawa $\mathrm{M}$ : No-touch pancreatectomy for invasive ductal carcinoma of the pancreas. J Pancreas 15 : 243-249, 2014

7. Traverso LW, Longmire WJ : Preservation of the pylorus in pancreaticoduodectomy. Surg Gynecol Ostet 146 : 959-962, 1978

8. Zerbi A, Balzano G, Patuzzo R, Calori G, Braga M, Di Cario V : Comparison between pylorus-preserving and Whipple pancreatoduodenectomy. Br J Surg 82 : 975- 979,1995 
9. Mosca F, Giulianotti PC, Balestracci T, Di candio G, Pietrabissa A, Sbrana F, Rossi G : Long-term survival in pancreatic cancer : pylorus-preserving versus Whipple pancreatoduodenectomy. Surgery $122: 553-566,1997$

10. Klinkenbijl JH, van der Schelling GP, Hop WC, van Pel R, Bruining HA, Jeekel $\mathrm{J}$ : the advantages of pylorus-preserving pancreatoduodenectomy in malignant disease of the pancreas and periampullary region. Ann Surg $216: 142-145,1992$

11. Takada T, Yasuda H, Amano H, Yoshida M, Ando H : Results of a pylorus-preserving pancreatoduodenectomy for pancreatic cancer : A comparison with results of the Whipple procedure. Hepatogastroenterology $44: 1536-1540,1997$

12. Schniewind B, Bestmann B, Henne-Bruns D, Faendrich F, Kremr B, Kuechler T: Quality of life after pancreaticoduodenectomy for ductal adenocarcinoma of the pancreatic head. Br J Surg 93 : 1099-1107, 2006

13. Yang C, Wu HS, Chen XL, Wang CY, Gou SM, Xiao J, He ZQ, Chen QJ, Li YF : Pylorus-preserving versus pylorus-resecting pancreaticoduodenectomy for periampullary and pancreatic carcinoma : A meta-analysis. Plos One 9 : e90316, 2014

14. Niedergethmann M, Snang E, Farag Soliman M, Saar J, Berisha S, Willeke F, Post S : Early and enduring nutritional and functional results of pylorus preservation vs classic Whipple procedure for pancreatic cancer. Langenbecks Ach Surg $391: 195-202,2006$

15. Wente MN, Bassi C, Dervenis C, Fingerhut A, Gouma DJ, Izbicki JR, Neoptolemos JP, Padbury RT, Sarr MG, Traverso LW, Yeo CJ, Buchler MW : Delayed gastric emptying (DGE) after pancreatic surgery : a suggested definition by the International Study Group of Pancreatic Surgery (ISGPS). Surgery $142: 761-768,2007$

16. Akizuki E, Kimura Y, Nobuoka T, Imamura M, Nagayama M, Sonoda T, Hirata K : Reconsidaration of postoperative oral intake tolerance after pancreaticoduodenectomy-prospective consecutive analysis of delayed gastric empting according to the ISGPS definition and the amount of dietary intake. Ann Surg 249 : 986-994, 2009

17. Hashimoto Y, Traverso LW : Incidence of pancreatic anastomotic failure and delayed gastric emptying after pancreatoduodenectomy in 507 cosecutive patients : Use of aweb-based calculator to improve homogeneity of definition. Surgery 147 : 503-515, 2010

18. Yamaguchi K, Tanaka M, Chijiwa K, Nagakawa T, Imamura M, Takada T : Early and late complications of pylorus-preserving pancreatoduodenectomy in Japan 1998. J Hepato-Biliary Pancreat $6: 303-311,1999$

19. Poon RT, Fan ST, Lo CM, Ng KK, Yuen WK, Yeung C, Wong $\mathrm{J}$ : External drainage of pancreatic duct with a stent to reduce leakage rate of pancreaticojejunostomy after pancreticoduodenectomy : a prospective randomized trial. Ann Surg 246 : 425-433, 2007

20. Winter JM, Cameron JL, Campbell KA, Chang DC, Riall TS, Schulick RD, Choti MA, Coleman J, Hodgin MB, Sauter PK, Sonnenday CJ, Wolfgang CL, Marohn MR, Yeo CJ : Does pancreatic duct stenting decrease the rate of pancreatic fistula following pancreaticoduodenectomy? Results of a prospective randomized trial. J Gastrointest Surg 10 : 1280-1290, 2006

21. Bassi C, Devervenis C, Butturini G, Finggerhut A, Yeo C, Izbicki J, Neoptolemos J, Sarr M, Traverso W, Buchler M, International Study Group on Pancreatic Fistula Definition : Postoperative pancreatic fistula : an international study group (ISGPF) definition. Surgery $138: 8-13,2005$

22. Went MN, Veit JA, Bassi C, Dervenis C, Fingerhut A, Gouma DJ, Izbicki JR, Neoptolemos JP, Sarr MG, Yeo CJ, Buchler $\mathrm{M}$ : Postoppancreatectomy hemorrhage (PPH) : an International Study Group of pancreatic surgery (ISGPS) definition. Surgery $142: 20-25,2007$

23. Kawai M, Tani M, Terasawa $H$, Ina S, Hirono S, Nishioka R, Miyazawa M, Uchiyama K, Yamaue H : Early removal of prophylactic darains reduces the risk of intra-abdominal infections in patients with pancreatic head resection ; Prospective study for 104 consecutive patients. Ann Surg 244 : 1-7, 2006

24. Bassi C, Molinari E, Malleo G, Crippa S, Butturini G, Salvia R, Talamini G, Pederzoli P : Early versus late removal after standard pancreatic resection ; results of a prospective randomized trial. Ann Surg $252: 207-214,2010$

25. Pancreatic Cancer Clinical Practice Guidelines, 2013 version, Japan Pancreas Society, Kanehara \& Co., Ltd., Tokyo, pp7677,2013 